\title{
Does dissatisfaction with, or accurate perception of overweight status help people reduce weight? Longitudinal study of Australian adults
}

Xiaoqi Feng ${ }^{1,2^{*}}$ and Andrew Wilson ${ }^{2,3}$

\begin{abstract}
Background: With studies around the world suggesting a large proportion of people do not recognise that they are overweight (or feel satisfied with being overweight), this fuels the view that such 'misperceptions' need to be 'corrected'. However, few longitudinal studies have examined the consequences of under-perceived weight status, nor over-perceived weight status (when a person feels overweight when they are not) and weight-related satisfaction on trajectories in body mass index (BMI).
\end{abstract}

Methods: Five-year BMI trajectories were examined among 8174 participants in an Australian nationally representative cohort. Each person was classified into groups according to their neighbourhood socioeconomic circumstances, baseline BMI and answers to "how satisfied are you with your current weight?" and "do you consider yourself to be... acceptable weight / underweight / overweight?" Gender-specific multilevel linear regressions were used to examine five-year BMI trajectories for people in each group, adjusting for potential confounders.

Results: At baseline, weight-related dissatisfaction and perceived overweight were generally associated with higher mean BMI for men and women, regardless of whether they were classified as 'normal' or overweight by World Health Organization (WHO) criteria. Mean BMI did not decrease among people classified as overweight who perceived themselves as overweight, or expressed weight-related dissatisfaction, regardless of where they lived. Among men and women with 'normal' BMI at baseline but expressing weight-related dissatisfaction, mean BMI increased disproportionately among those living in disadvantaged areas compared to their counterparts in affluent areas. Similarly, mean BMl rose disproportionately among people in disadvantaged areas who felt they were overweight despite having a 'normal' BMI by WHO criteria, compared to people with the same overperceptions living in affluent areas. These differences exacerbated pre-existing socioeconomic inequities in mean BMI.

Conclusions: No evidence was found to suggest accurate recognition of overweight or expressing weight-related dissatisfaction leads to a lower BMI. However, there was evidence of an increase in mean BMI among people who felt dissatisfied with, or over-perceived their 'normal' weight, especially in socioeconomically disadvantaged areas. Correction of under-perceptions may not drive weight loss, but circumstances contributing to over-perception and dissatisfaction with weight status may contribute to increased weight gain and exacerbate socioeconomic inequities in BMl.

Keywords: Body mass index, Weight misperception, Disadvantage, Longitudinal

\footnotetext{
* Correspondence: xfeng@uow.edu.au

'Population Wellbeing and Environment Research Lab (PowerLab), School of Health and Society, Faculty of Social Sciences, University of Wollongong, Wollongong, NSW 2522, Australia

${ }^{2}$ Menzies Centre for Health Policy, School of Public Health, the Faculty of

Medicine and Health, The University of Sydney, Sydney, Australia

Full list of author information is available at the end of the article
}

(c) The Author(s). 2019 Open Access This article is distributed under the terms of the Creative Commons Attribution 4.0 International License (http://creativecommons.org/licenses/by/4.0/), which permits unrestricted use, distribution, and reproduction in any medium, provided you give appropriate credit to the original author(s) and the source, provide a link to the Creative Commons license, and indicate if changes were made. The Creative Commons Public Domain Dedication waiver (http://creativecommons.org/publicdomain/zero/1.0/) applies to the data made available in this article, unless otherwise stated. 


\section{Background}

Weight gain among people living in disadvantaged neighbourhoods in high-income countries is comparatively higher and begins earlier than their peers in more affluent areas, especially for women [1-3]. Some longitudinal studies of adults in Australia [4] and the US [5] report comparatively greater weight gain over time among people who considered their weight status as 'normal', but were actually overweight or obese by World Health Organization (WHO) criteria. Evidence suggests under-perception of weight status is common [6-13]. Conventional wisdom suggests that correction of this 'under-perception' is a pre-requisite for behavioural change to achieve weight loss, or the slowing of the rate of weight gained over time [14, 15]. Evidence indicates there has been increased efforts by health professionals to correct under-perception of weight status in the US over the last 15 years [16].

However, some evidence suggests that under-perception of overweight status may be sometimes favourable. A recent systematic review found evidence to indicate that people who perceive their weight status as overweight were likely to gain more weight over time, despite also being more likely to attempt weight loss behaviours [17]. Studies of children have reported under-perception of overweight status to be associated with lower future weight gain [18] and lower blood pressure trajectories [19]. Meanwhile, there are some other studies that report problems with over-perception, or when people of 'normal' weight by WHO criteria perceive themselves as overweight or obese. Over-perception is common in some groups [20] and has been linked to future weight gain in adults $[21,22]$ and also contributing factors, such as increased psychological distress [23]. Similar findings have been reported in children and adolescents [24, 25]. Rather than being detrimental, under-perception of weight status may sometimes be protective (or indicative of the presence of some other protective factor, such as positive affect) against weight-related stigma and media-driven portrayals of idealised body size, which have been suggested to lead to heightened stress and maladaptive behaviours that contribute to weight gain $[26,27]$.

Satisfaction with current weight status has also been suggested to play a role in determining future weight loss. Studies have shown that body dissatisfaction and concern over weight and body shape intensify across adolescence [28], but then remain largely stable (particularly for women) for the rest of the lifecourse, despite physical changes associated with ageing [29]. Much of the research on body satisfaction and weight gain has been conducted on adolescents, with many studies finding more weight-related dissatisfaction among overweight adolescents to be predictive of future weight gain and maladaptive behaviours such as binge eating [30-34]. These findings run counter to belief that dissatisfaction with overweight status is a necessary precursor for positive change.
The abovementioned evidence provides interesting but conflicting perspectives on whether correction of under-perceived weight status ought to be mainstream policy. On one hand, correction of under-perception may be seen to enable people to take action and perhaps, in some contexts, receive additional support services (e.g. enrolment in a behavioural change program). But on the other, the psychosocial stress associated with being labelled as overweight or obese, even if a person is overweight by WHO criteria, may have unintended consequences, such as compounding body dissatisfaction. Since the majority of evidence is from the US, more studies are warranted to understand if either of these duelling hypotheses are supported in other contexts. It is possible that evidence for both hypotheses within the same national context may be available due to heterogeneity of experience between population sub-groups, such as well-known differences in weight-related stigma and discrimination experienced between men and women [35, 36].

Furthermore, it is plausible that different experiences will manifest across strata of area-level socioeconomic circumstances due to variation in the visual normalisation of overweight status [37]. In communities where being overweight or obese by WHO criteria is the norm, visual normalisation theory suggests that the BMI threshold by which people judge themselves to be overweight is raised [37]. In many countries the prevalence of overweight and obesity is at or above $60 \%$, and within those countries overweight and obesity tend to be higher in socioeconomically disadvantaged areas [38]. This suggests the possibility of visual normalisation patterned geographically within countries. Recent studies report under-perception is more common among adults in socioeconomically disadvantaged areas [39] and in children of families with low educational attainment [40], perhaps because of visual normalisation [37] of larger body sizes. This may exacerbate the effect of other factors that contribute to the 'obesogenic' environment in disadvantaged areas, such as higher ratios of unhealthy to healthy food outlets [41] and visual cues that stimulate appetite for unhealthy food [42].

Accordingly, the purpose of this study was to examine five-year trajectories in body mass index (BMI) among male and female Australian adults stratified by their WHO criteria-defined weight status at baseline. Differences in BMI trajectories in each of these groups were examined in relation to each person's perception of and satisfaction with their baseline weight status, as well as the potential for effect modification by area-level socioeconomic circumstances.

\section{Methods}

Data

Data analysed in this study was extracted from the "Household, Income and Labour Dynamics in Australia" 
(HILDA). Details of HILDA are already published [43]. In brief, HILDA is a nationally representative sample of approximately 15,000 individuals in 7000 households collected annually. A longitudinal sample of 4386 men and 3788 women aged $\geq 15$ years with complete BMI data in 2007 and 2012 was selected. These waves were selected as 2007 was the first year in which questions of perceived weight and weight-related satisfaction were asked, while data from 2012 was the most recent wave that was available at the time of analysis. Participants considered 'underweight' by WHO criteria $(\mathrm{BMI}<18.5$ $\mathrm{kg} / \mathrm{m}^{2}$ ) were omitted as our focus was on contrasting people who were overweight or obese (BMI $\left.\geq 25 \mathrm{~kg} / \mathrm{m}^{2}\right)$ with those classified as 'normal' (BMI $\geq 18.5 \mathrm{~kg} / \mathrm{m}^{2}$ and $<25 \mathrm{~kg} / \mathrm{m}^{2}$ ).

\section{Body mass index and initial weight status}

Self-reported height and weight were used to calculate BMI for each participant. BMI was considered in its continuous form for the outcome variable. Initial weight status was the BMI category at baseline (in 2007).

\section{Weight related perceptions}

Two questions on weight-related perceptions were asked in the 2007 survey. The first asked "How satisfied are you with your current weight". Answers were "very satisfied,' 'satisfied,' 'neither satisfied nor dissatisfied,' 'dissatisfied', 'very dissatisfied' or 'refused/not stated'. We classified these answers into 'dissatisfied' ('dissatisfied, 'very dissatisfied'), 'not dissatisfied/ambivalent' ('very satisfied,' 'satisfied, 'neither satisfied nor dissatisfied') or 'other' ('refused/not stated'). The second indicator was self-rated weight status, as follows: "Do you consider yourself to be... acceptable weight / underweight / overweight?" Answers were classified into 'acceptable, 'overweight' or 'other'.

\section{Neighbourhood socioeconomic disadvantage}

The Australian Bureau of Statistics (ABS) Socio Economic Indices For Areas (SEIFA) was used to measure neighbourhood socioeconomic disadvantage. The index selected for this study was of relative disadvantage, a composite indicator derived via principal components analysis by the Australian Bureau of Statistics to summarise multiple census data on income, education, employment, occupation, housing and other indicators of relative disadvantage (e.g. no car ownership) [44]. Lower values on this index denote an increasing concentration of disadvantaged people. As our focus was on disadvantaged communities and required stratification for purposes of comparing associations between weight change and weight-related (mis)perceptions across different levels of neighbourhood socioeconomic circumstances, this variable was inverted and then classified into tertiles so that higher strata denoted more disadvantaged areas. Our previous work $[3,45,46]$ and that of others internationally [47] has shown that residents (especially women) in socioeconomically disadvantaged neighbourhoods tend to have higher BMI on average and independent of related factors such as educational attainment, employment status and household income. In this study, this measure of neighbourhood socioeconomic circumstances was utilised as a potential effect modifier, to reveal plausible differences in weight change trajectories over time between people living in disadvantaged and affluent areas with different stated perceptions of their weight at baseline.

\section{Potential confounding variables}

A range of variables were identified to reduce probable sources of confounding based upon a synthesis of previous literature [47-49]. These included age, whether a participant was living on their own or as part of a couple (married or cohabiting), the highest level of education achieved (less than high school, high school to advanced diploma, university or higher), average household gross income (expressed in quintiles), the percentage of time in the last year spent unemployed, and geographic remoteness. Geographic remoteness was measured using the Accessibility/Remoteness Index of Australia (ARIA) [50], which helped to distinguish between participants living in urban areas (defined by the "major city" category) and or regional and remote areas (defined by those living in "inner regional", "outer regional", "remote" and "very remote" areas of Australia).

\section{Analytical strategy}

The sample was described using cross-tabulations and mean BMIs at baseline and follow-up for each covariate. Multilevel linear regression models were used to investigate associations between BMI trajectories between baseline and follow-up with respect to neighbourhood disadvantage, initial weight status and the perceived weight status variables, adjusting for confounders. This was implemented by cross-classifying actual weight status at baseline with the weight-related perception variables, then fitting two-way interaction terms followed by a three-way interaction term between this cross-classified actual vs. perceived weight variable, neighbourhood disadvantage and time. These models were fitted separately for men and women due to known differences in risk of experiencing weight-related discrimination. The multilevel models were used to take account clustering of participants (level 1) within households (level 2) and areas of residence (level 3) as reported at baseline. Neighbourhoods were defined as Census Collection Districts ('CCDs'), which are small areas containing approximately 225 residential dwellings 
on average. Results were presented using adjusted predicted mean BMI trajectories with 95\% confidence intervals (95\%CIs) from these models. All analyses were conducted in MLwIN v2.30 [51]. Ethical approval for the HILDA study was obtained from the Faculty of Business and Economics Human Ethics Advisory Committee at the University of Melbourne. Approval for the use of HILDA data was provided by the Government Department of Social Services.

\section{Results}

Table 1 shows mean BMI was slightly higher in more disadvantaged neighbourhoods among men (correlation coefficient $=0.07, \quad p<0.0001$ ) and especially women $(0.12, p<0.0001)$. BMI tended to be appreciably higher among participants reporting dissatisfaction with their weight (correlation coefficient: men $=0.37, p<0.0001$; women $=0.41, p<0.0001)$ and perceiving themselves as overweight (correlation coefficient: men $=0.54, \quad p<$ 0.0001 ; women $=0.55, p<0.0001$ ). Mean BMI varied by age, couple status, highest educational qualification and percentage of the previous year spent unemployed, but less so across quintiles of annual household income and the geographic remoteness of the place of residence.

Statistically significant $(p<0.001)$ chi-square values of the weight-related perception and satisfaction variables, both overall and for men and women separately, suggested an imperfect correlation between perceived overweight and dissatisfaction with current weight status. Table 2 shows the extent that unadjusted mean BMI for men and women at baseline varied with respect to a cross-classification of actual weight status and perception of weight. Among men with a 'normal' BMI by WHO criteria, those expressing dissatisfaction with their weight had a lower BMI compared to their peers who did not. The opposite pattern was observed for women of 'normal' BMI. The perception of being overweight was associated with higher BMI for men and women regardless of whether they were actually overweight or 'normal'. Some of these patterns at baseline appeared to vary by neighbourhood disadvantage. For example, men expressing dissatisfaction despite having 'normal' weight had lower BMI if living in a disadvantaged neighbourhood $\left(\right.$ mean $\left.=20.7 \mathrm{~kg} / \mathrm{m}^{2}\right)$, compared to their peers in the same BMI category also expressing dissatisfaction but living in more affluent areas $\left(\right.$ mean $\left.=22.2 \mathrm{~kg} / \mathrm{m}^{2}\right)$.

Predicted mean BMI trajectories and 95\% confidence intervals from gender-stratified fully adjusted multilevel models with interactions between time, neighbourhood disadvantage and the cross-classification of baseline weight status and weight-related satisfaction and are shown in Fig. 1. Figure 2 shows virtually the same models, except perceived weight status was substituted in for weight-related satisfaction. Both figures reveal a complex range of trajectories in BMI change across these groups. The multilevel models on which the means were predicted for Figs. 1 and 2 are provided in Additional file 1: Table S1 and Additional file 2: Table S2, respectively.

In Fig. 1, men and women who were already overweight did not appear to gain or lose much weight between baseline and follow-up. This was regardless of whether participants felt dissatisfied with their weight or not. In contrast, Fig. 1 also shows gains in weight among men and women who began the study having 'normal' weight by WHO criteria. These gains were observed for persons who felt dissatisfied with their weight and those who did not. These patterns were consistent across strata of neighbourhood socioeconomic disadvantage.

In Fig. 2, as with Fig. 1, people who were overweight at baseline tended not to gain or lose weight on average across the 5 years. Weight gain was seen among people who had a 'normal' BMI by WHO criteria at baseline. Weight gain was observed for people who perceived themselves as being overweight, especially among men and women in disadvantaged neighbourhoods. People who felt their weight was acceptable gained weight.

\section{Discussion}

In our study, the first notable finding is that among people who were overweight or obese at baseline, people did not gain or lose weight (on average) regardless of whether they perceived themselves as overweight or not. The same results were observed when focussing on whether a person expressed dissatisfaction with their weight at baseline. Second, weight gain was more common for men and women who had a 'normal' weight status at baseline by WHO criteria, but a little more rapid for those who perceived themselves to be overweight or dissatisfied with their weight. Third, this weight gain among people who over-perceived their 'normal' weight status was greater for those living in disadvantaged neighbourhoods.

Our findings reflect an interplay between actual weight status, perceived weight status and neighbourhood disadvantage. It is not fully clear at the present time what explains these findings, though it may be helpful to rule some explanations out. First, people who under-perceived their overweight did not substantially gain more weight, though neither did they appear to lose weight on average. Some previous studies have suggested the possibility of a protective mis-perception of weight status among children $[18,19]$, wherein under-perception of overweight may help reduce the probability of gaining weight over time (or be indicative of other, unmeasured, protective factors). As little change occurred among people who were overweight regardless of their perception or level of satisfaction, this 
Table 1 Description of the study sample at baseline (wave 7) and 5-year follow-up (wave 12)

\begin{tabular}{|c|c|c|c|c|c|c|}
\hline & \multicolumn{3}{|l|}{ Men } & \multicolumn{3}{|l|}{ Women } \\
\hline & \multirow{2}{*}{$\begin{array}{l}\text { N (\%) } \\
\text { (Baseline) }\end{array}$} & \multicolumn{2}{|c|}{ Body Mass Index (mean) } & \multirow{2}{*}{$\begin{array}{l}\mathrm{N} \\
\text { (Baseline) }\end{array}$} & \multicolumn{2}{|c|}{ Body Mass Index (mean) } \\
\hline & & Baseline & 5-year follow-up & & Baseline & 5-year follow-up \\
\hline N & 4386 & 26.9 & 27.4 & 3788 & 26.1 & 26.8 \\
\hline \multicolumn{7}{|l|}{ Disadvantage tertiles } \\
\hline Affluent & $1381(36.5 \%)$ & 26.4 & 26.9 & 1561 (35.6\%) & 25.2 & 25.9 \\
\hline Average & $1261(33.3 \%)$ & 27.0 & 27.8 & 1494 (34.1\%) & 26.2 & 26.9 \\
\hline Disadvantaged & 1146 (30.3\%) & 27.3 & 27.7 & 1331 (30.4\%) & 27.1 & 27.6 \\
\hline \multicolumn{7}{|l|}{ Dissatisfied } \\
\hline No/ambivalent & $2640(69.7 \%)$ & 25.6 & 26.3 & $2422(55.2 \%)$ & 23.9 & 24.7 \\
\hline Yes & $1138(30.0 \%)$ & 29.8 & 30.1 & $1940(44.2 \%)$ & 29.0 & 29.5 \\
\hline Missing & $10(0.3 \%)$ & 26.9 & 27.5 & $24(0.6 \%)$ & 25.0 & 26.6 \\
\hline \multicolumn{7}{|l|}{ Perception } \\
\hline Acceptable & $2174(57.4 \%)$ & 25.0 & 25.7 & $2290(52.2 \%)$ & 23.2 & 24.0 \\
\hline Overweight & 1391 (36.7\%) & 30.6 & 30.9 & 1942 (44.3\%) & 30.0 & 30.5 \\
\hline Missing & $223(5.9 \%)$ & 21.2 & 22.6 & $154(3.5 \%)$ & 20.2 & 21.4 \\
\hline \multicolumn{7}{|l|}{ Age group } \\
\hline $15-24$ & $557(14.7 \%)$ & 23.9 & 25.2 & $671(15.3 \%)$ & 23.5 & 24.4 \\
\hline $25-34$ & $549(14.5 \%)$ & 26.7 & 26.4 & $675(15.4 \%)$ & 25.8 & 25.9 \\
\hline $35-44$ & $732(19.3 \%)$ & 27.3 & 27.9 & $851(19.4 \%)$ & 26.4 & 27.1 \\
\hline $45-54$ & $797(21.0 \%)$ & 27.7 & 28.1 & 855 (19.5\%) & 26.8 & 27.1 \\
\hline $55-64$ & $590(15.6 \%)$ & 28.1 & 28.2 & $693(15.8 \%)$ & 27.7 & 27.9 \\
\hline $65-74$ & $404(10.7 \%)$ & 27.1 & 27.9 & 417 (9.5\%) & 26.5 & 27.5 \\
\hline $75+$ & $159(4.2 \%)$ & 26.2 & 26.1 & $224(5.1 \%)$ & 26.2 & 26.0 \\
\hline \multicolumn{7}{|l|}{ Couple status } \\
\hline Yes & $2652(70.0 \%)$ & 27.4 & 27.7 & $2814(64.2 \%)$ & 26.4 & 26.9 \\
\hline No & $1136(30.0 \%)$ & 25.7 & 26.8 & $1571(35.8 \%)$ & 25.6 & 26.6 \\
\hline Refused & $0(0.0 \%)$ & 0.0 & 0.0 & & & \\
\hline \multicolumn{7}{|l|}{ Education } \\
\hline$<=$ year $11 \%$ & $1044(27.6 \%)$ & 26.8 & 28.0 & 1664 (37.9\%) & 26.5 & 27.7 \\
\hline Year 12 to adv diploma\% & $1892(50.0 \%)$ & 27.0 & 27.5 & 1676 (38.2\%) & 26.2 & 26.8 \\
\hline university & $850(22.4 \%)$ & 26.6 & 26.8 & $1045(23.8 \%)$ & 25.4 & 25.8 \\
\hline undetermined & $2(0.1 \%)$ & 26.3 & 26.8 & $1(0.0 \%)$ & 24.3 & 23.4 \\
\hline \multicolumn{7}{|l|}{ Percent unemployed } \\
\hline $0 \%$ & $3558(93.9 \%)$ & 26.9 & 27.4 & 4090 (93.3\%) & 26.1 & 26.8 \\
\hline $1-24 \%$ & $95(2.5 \%)$ & 26.2 & 28.4 & $112(2.6 \%)$ & 25.3 & 25.9 \\
\hline $25-49 \%$ & $47(1.2 \%)$ & 25.3 & 26.7 & $68(1.6 \%)$ & 25.5 & 28.0 \\
\hline $50-74 \%$ & $36(1.0 \%)$ & 26.0 & 27.1 & $45(1.0 \%)$ & 28.0 & 25.7 \\
\hline $75-100 \%$ & $52(1.4 \%)$ & 26.0 & 26.8 & $71(1.6 \%)$ & 27.2 & 27.8 \\
\hline \multicolumn{7}{|l|}{ Income quintiles } \\
\hline 1 (low) & 745 (19.7\%) & 27.1 & 27.2 & 1082 (24.7\%) & 26.8 & 27.1 \\
\hline 2 & $840(22.2 \%)$ & 26.7 & 27.6 & 976 (22.3\%) & 26.3 & 27.1 \\
\hline 3 & $902(23.8 \%)$ & 26.8 & 27.4 & $951(21.7 \%)$ & 26.4 & 27.1 \\
\hline 4 & 729 (19.2\%) & 27.0 & 27.6 & 787 (17.9\%) & 25.6 & 26.9 \\
\hline 5 (high) & $572(15.1 \%)$ & 26.7 & 27.3 & $590(13.5 \%)$ & 24.9 & 26.0 \\
\hline
\end{tabular}


Table 1 Description of the study sample at baseline (wave 7) and 5-year follow-up (wave 12) (Continued)

\begin{tabular}{|c|c|c|c|c|c|c|}
\hline & \multicolumn{3}{|l|}{ Men } & \multicolumn{3}{|l|}{ Women } \\
\hline & \multirow{2}{*}{$\begin{array}{l}\text { N (\%) } \\
\text { (Baseline) }\end{array}$} & \multicolumn{2}{|c|}{ Body Mass Index (mean) } & \multirow{2}{*}{$\begin{array}{l}\mathrm{N} \\
\text { (Baseline) }\end{array}$} & \multicolumn{2}{|c|}{ Body Mass Index (mean) } \\
\hline & & Baseline & 5-year follow-up & & Baseline & 5-year follow-up \\
\hline \multicolumn{7}{|c|}{ Geographic remoteness } \\
\hline Major city & $2338(61.7 \%)$ & 26.7 & 27.3 & 2719 (62.0\%) & 26.0 & 26.5 \\
\hline Inner regional & $961(25.4 \%)$ & 27.1 & 27.6 & $1112(25.4 \%)$ & 26.2 & 27.1 \\
\hline Outer regional & $430(11.4 \%)$ & 27.2 & 28.0 & $482(11.0 \%)$ & 26.9 & 27.5 \\
\hline remote & 59 (1.6\%) & 27.5 & 28.2 & 73 (1.7\%) & 26.3 & 27.6 \\
\hline
\end{tabular}

does not provide evidence to support the protective mis-perception hypothesis. Nor does it provide evidence to support the mainstreaming of attempts to correct for under-perceptions of overweight status. Additionally, visual normalisation of overweight may not only make it acceptable within certain contexts to be heavier by raising the lower threshold of what is considered overweight [5254], but it too may also provide an adjusted upper threshold as to what is generally felt to be too heavy for most people. This is an area that needs further research.

Our study does provide evidence for potentially correcting over-perceptions of weight status among people with a 'normal' BMI according to WHO criteria. Previous work has identified that people who perceive themselves as overweight have a higher probability of going on to gain weight [17], though fewer studies have differentiated between people who had a 'normal' BMI by WHO criteria from people who were actually overweight. A range of factors may be at play. First, regular exposure to media and advertising-driven portrayals of ideal body shapes and weights may be one reason why people may perceive themselves as overweight when they are not. Previous work has suggested that both men and (especially) women, tend to feel less satisfied with their bodies or be more likely to consider themselves overweight after viewing pictures of thin people (e.g. on television) [55-60].

These negative comparisons may spur a range of possible responses, some of which may be patterned by neighbourhood socioeconomic circumstances. One being emotional decision-making and engagement in maladaptive behaviours $[26,27]$ associated with 'future discounting'. This is when people trade off the long-term consequences of alcohol and binge eating food packed with sugar and carbohydrates to satisfy short-term needs to mask feelings of shame, hopelessness and a lack of control $[61,62]$. It is perhaps more likely to occur among people in disadvantaged areas who may feel they have few other options, while being encouraged by local obesogenic food environment providing numerous cues and opportunities to purchase junk food [41, 42]. By contrast, it is known that people in more affluent circumstances tend to have more healthier food environment (or at least healthier options) and be more likely to monitor their weight and engage in diet management [63].

Comfort eating of calorific food is compounded by the release of glucocorticoids that increases a person's appetite for food that gives them pleasure under stressful situations $[64,65]$. It is known that people in disadvantaged neighbourhoods experience chronic levels of stress more often than their peers in more affluent circumstances [66]. Although there were no consistent gender differences found in our study, women may be especially vulnerable to maladaptive behaviours [67-69], since there is greater value placed on female physical attractiveness [70] and a lower tolerance over minor weight gain among women than there is for men [71-73].

Further socioeconomic patterning may be driven by who or what people feel is the driver of their over-perceived weight status. An experimental study showed people with heavier BMI living in more affluent circumstances were more willing to excuse their body weight as something that was not entirely within their control, whereas people with higher BMI in more disadvantaged surroundings were more likely to blame themselves for their weight status [70]. Evidence also suggests that as body size increases, which will have been more dramatic among those in our study who had 'normal' BMI at baseline, women (but not men) tend to disconnect from social activities [74, 75], potentially increasing the risk of social isolation and associated behaviours such as eating disorders [76]. All of these factors may help to explain greater weight gain among people who over-perceived their weight status, and especially those in disadvantaged areas, though further research is warranted.

The study benefits from panel data over a 5-year period containing rich information, including a range of socioeconomic and demographic variables on a large number of men and women stratified by neighbourhood socioeconomic circumstances, WHO-defined BMI category and whether they perceived themselves as overweight and/or felt dissatisfied with their weight status. The longitudinal design afforded insights into different mean BMI 


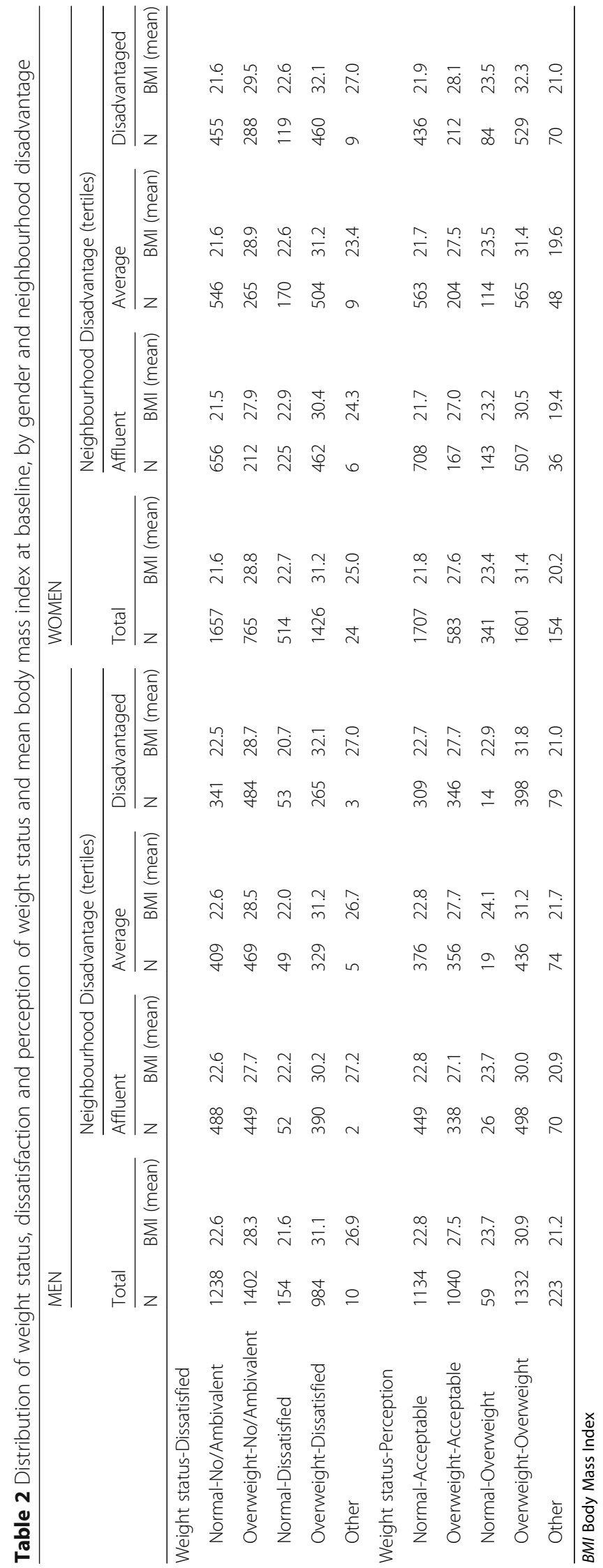




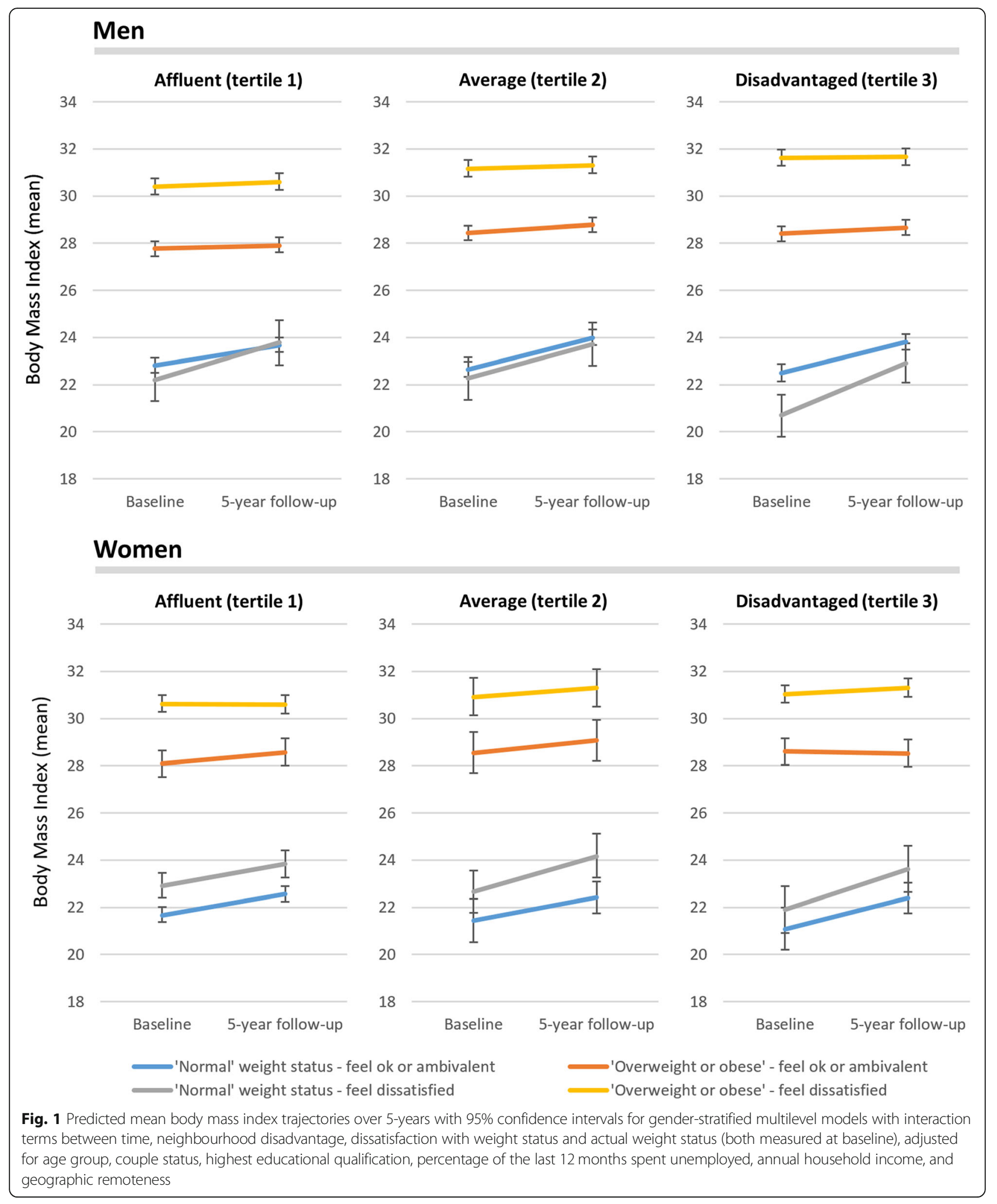

trajectories over 5 years across all of these groups, potentially for the first time within a single study. The multilevel approach permitted a disentangling of effects between people and their places of residence and allowed assessment of change in BMI, while taking into account variation in mean baseline values between each group.

Some of the limitations and areas for future study include small sample sizes for ethnic groups, which would 


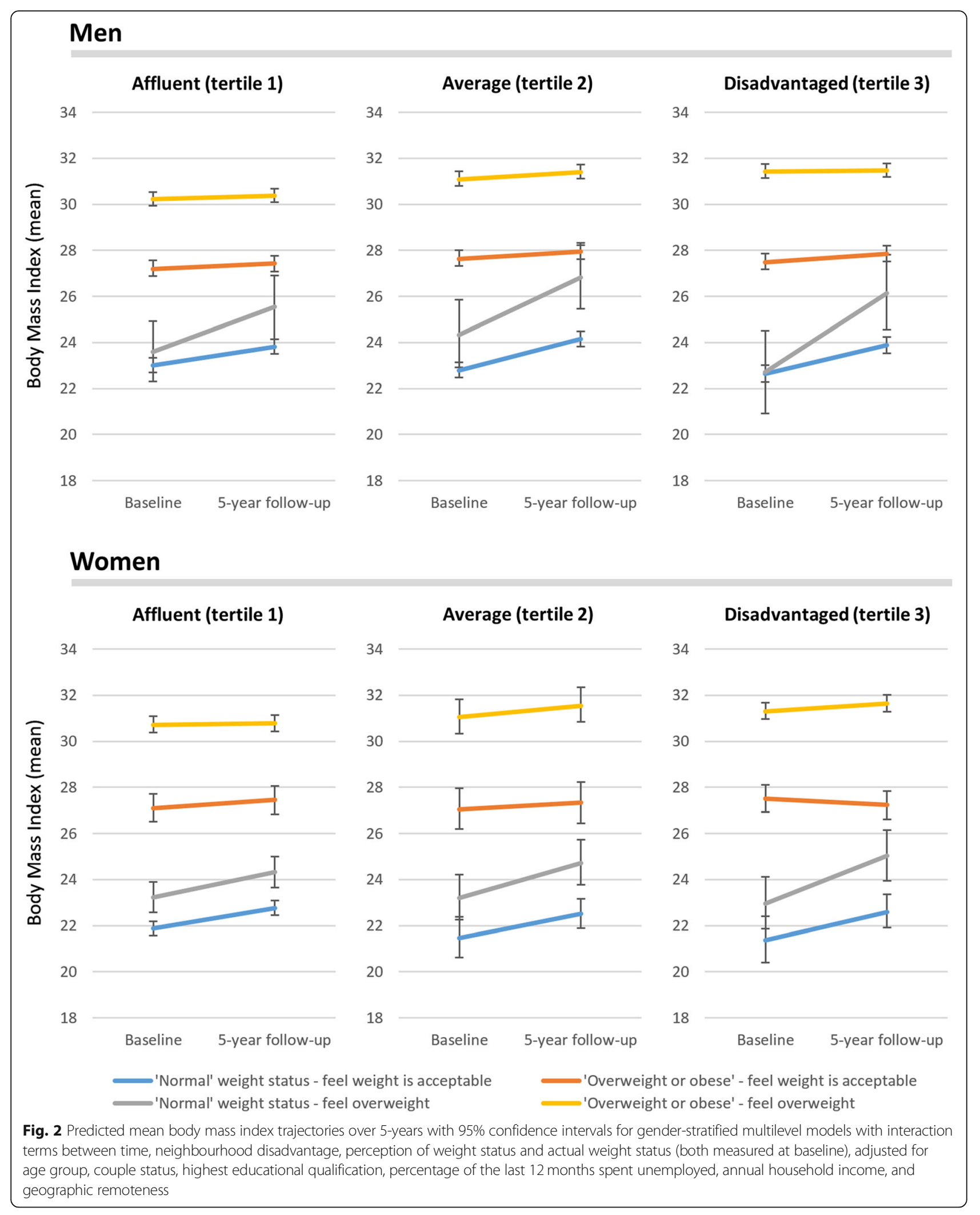


have been interesting to examine given prior work suggesting variations in weight-related perceptions between people of different ethnicities and countries of birth [77-80]. Another limitation is the known underreporting of weight and over-reporting of height [81], which means that the BMI variable used in our study can really only be considered a proxy for actual weight status. Studies that can replicate our longitudinal design but incorporate objectively measured BMI and/or other relevant outcome variables such as waist circumference and percentage abdominal fat would prove valuable next steps. It is important to note that this study is based upon observational data in which none of the perceptions of weight status, nor other variables analysed such as neighbourhood disadvantage, can be considered randomly assigned. As such, some residual confounding may remain even after multivariate adjustment. Finally, it would also be novel to examine not only whether mean BMI trajectories continue over a longer time-period among the groups in our study, but also to see at what point perceptions of weight change (if at all) over time.

\section{Conclusions}

The findings of this study indicate, if interpreted in a causal sense and with caution, that practices to correct weight-related misperceptions may not be effective in promoting weight loss. We observed no weight loss (or gain) on average among people already overweight or obese at baseline regardless of their weight-related perception or satisfaction. In contrast, people who had a 'normal' weight at baseline by WHO criteria gained weight on average, especially among those who were dissatisfied with their weight, or who perceived themselves as overweight, in disadvantaged neighbourhoods. Randomised trials are warranted to examine the extent that these findings are robust to experimental design.

\section{Additional files}

Additional file 1: Table S1. Multilevel models of five-year change in body mass index for men and women, accounting for potential effect modification of baseline actual weight status and satisfaction with weight status across strata of neighbourhood socioeconomic disadvantage. (DOCX $37 \mathrm{~kb}$ )

Additional file 2: Table S2. Multilevel models of five-year change in body mass index for men and women, accounting for potential effect modification of baseline actual weight status and perceived weight status across strata of neighbourhood socioeconomic disadvantage. (DOCX $37 \mathrm{~kb}$ )

\section{Abbreviations}

ABS: Australian Bureau of Statistics; ARIA: Accessibility/Remoteness Index of Australia; BMI: Body mass index; CCD: Census Collection Districts; HILDA: Household, Income and Labour Dynamics in Australia; SEIFA: Socio Economic Indices For Areas; US: United States; WHO: World Health Organization

\section{Acknowledgements}

This paper uses unit record data from the HILDA Survey. The HILDA Project was initiated and is funded by the Australian Government Department of Social Services (DSS), and is managed by the Melbourne Institute of Applied Economic and Social Research (Melbourne Institute). The findings and views reported in this paper, however, are those of the authors and should not be attributed to either the DSS or the Melbourne Institute. The Australian Prevention Partnership Centre is funded by the NHMRC, the Australian, NSW and ACT health departments, and the HCF Health and Medical Research Foundation.

\section{Funding}

No funding was received for this study.

\section{Availability of data and materials}

Data was accessed under a licence the result of a peer-reviewed application. Data is otherwise confidential and cannot be released by the authors. Those interested in accessing the data must contact the Melbourne Institute of Applied Economic and Social Research, Level 5, Business and Economics Building, 111 Barry Street, The University of Melbourne, Victoria 3010 Australia, Tel +61 38344 2108, Email hildainquiries@unimelb.edu.au.

\section{Authors' contributions}

Conceived and designed the study: XF AW. Performed the analysis: XF. Wrote the paper: XF AW. Both authors read and approved the final manuscript

\section{Ethics approval and consent to participate}

Ethical approval for HILDA was obtained from the Faculty of Business and Economics Human Ethics Advisory Committee at the University of Melbourne. Approval for the use of HILDA data was provided by the Government Department of Social Services.

\section{Consent for publication}

Not applicable.

\section{Competing interests}

The authors declare that they have no competing interests.

\section{Publisher's Note}

Springer Nature remains neutral with regard to jurisdictional claims in published maps and institutional affiliations.

\section{Author details}

${ }^{1}$ Population Wellbeing and Environment Research Lab (PowerLab), School of Health and Society, Faculty of Social Sciences, University of Wollongong, Wollongong, NSW 2522, Australia. ${ }^{2}$ Menzies Centre for Health Policy, School of Public Health, the Faculty of Medicine and Health, The University of Sydney, Sydney, Australia. ${ }^{3}$ The Australian Prevention Partnership Centre, The Sax Institute, Sydney, Australia.

Received: 2 March 2018 Accepted: 2 May 2019

Published online: 22 May 2019

\section{References}

1. Coogan PF, Cozier YC, Krishnan S, Wise LA, Adams-Campbell LL, Rosenberg L, Palmer JR. Neighborhood socioeconomic status in relation to 10-year weight gain in the black Women's health study. Obesity. 2010;18(10):20645.

2. Stafford M, Brunner EJ, Head J, Ross NA. Deprivation and the development of obesity: a multilevel, longitudinal study in England. Am J Prev Med. 2010; 39(2):130-9

3. Feng X, Wilson A. Getting bigger, quicker? Gendered socioeconomic trajectories in body mass index across the adult Lifecourse: a longitudinal study of 21,403 Australians. PLoS One. 2015;10(10):e0141499.

4. Hernan $A L$, Versace VL, Laatikainen T, Vartiainen E, Janus ED, Dunbar JA. Association of weight misperception with weight loss in a diabetes prevention program. BMC Public Health. 2014;14(1):93.

5. Herring SJ, Oken E, Haines J, Rich-Edwards JW, Rifas-Shiman SL, Gillman MW. Misperceived pre-pregnancy body weight status predicts excessive 
gestational weight gain: findings from a US cohort study. BMC Pregnancy Childbirth. 2008;8(1):54.

6. Johnson F, Cooke L, Croker H, Wardle J. Changing perceptions of weight in Great Britain: comparison of two population surveys. BMJ. 2008;337:a494

7. Salcedo V, Gutierrez-Fisac J, Guallar-Castillon P, Rodriguez-Artalejo F. Trends in overweight and misperceived overweight in Spain from 1987 to 2007. Int J Obes. 2010;34(12):1759-65.

8. Langellier BA, Glik D, Ortega AN, Prelip ML. Trends in racial/ethnic disparities in overweight self-perception among US adults, 1988-1994 and 1999-2008. Public Health Nutr. 2015;18(12):2115-2125.

9. Blokstra A, Burns C, Seidell J. Perception of weight status and dieting behaviour in Dutch men and women. Int J Obes. 1999:23(1):7-17.

10. Mogre V, Mwinlenna PP, Oladele J. Distorted self-perceived weight status and its associated factors among civil servants in tamale, Ghana: a crosssectional study. Arch Public Health. 2013;71(1):30

11. Caleyachetty R, Kengne AP, Muennig P, Rutter H, Echouffo-Tcheugui JB. Misperception of body weight among overweight or obese adults in Mauritius. Obes Res Clin Pract. 2016;10(2):216-9.

12. Tanenbaum HC, Felicitas JQ, Li Y, Tobias M, Chou C-P, Palmer PH, SpruijtMetz D, Reynolds KD, Johnson CA, Xie B. Overweight perception: associations with weight control goals, attempts, and practices among Chinese female college students. J Acad Nutr Diet. 2016;1 16(3):458-66.

13. Herbert J, Peterson KL, Alston L, Allender S, Nichols M. Comparison between measured and perceived weight status in a nationally representative sample of Australian adults. Obes Res Clin Pract. 2017;11:414-25.

14. Kuchler F, Variyam J. Mistakes were made: misperception as a barrier to reducing overweight. Int J Obes. 2003;27(7):856-61.

15. Brener ND, Eaton DK, Lowry R, McManus T. The association between weight perception and BMl among high school students. Obes Res. 2004;12(11):1866-74.

16. Hansen AR, Duncan D, Baidal JW, Hill A, Turner S, Zhang J. An increasing trend in health-care professionals notifying children of unhealthy weight status: NHANES 1999-2014. Int J Obes. 2016;40(10):1480.

17. Haynes A, Kersbergen I, Sutin A, Daly M, Robinson E. A systematic review of the relationship between weight status perceptions and weight loss attempts, strategies, behaviours and outcomes. Obes Rev. 2018;19(3):347-63.

18. Sonneville K, Thurston I, Milliren C, Kamody R, Gooding H, Richmond T. Helpful or harmful? Prospective association between weight misperception and weight gain among overweight and obese adolescents and young adults. Int J Obes. 2016:40(2):328-32.

19. Unger ES, Kawachi I, Milliren CE, Sonneville KR, Thurston IB, Gooding HC, Richmond TK. Protective misperception? Prospective study of weight selfperception and Blood pressure in adolescents with overweight and obesity. J Adolesc Health. 2017:60:680-7.

20. Strauss RS. Self-reported weight status and dieting in a cross-sectional sample of young adolescents: National Health and nutrition examination survey III. Arch Pediatr Adolesc Med. 1999:153(7):741-7.

21. Sutin AR, Terracciano A. Perceived weight discrimination and obesity. PLoS One. 2013;8(7):e70048.

22. Robinson E, Hunger J, Daly M. Perceived weight status and risk of weight gain across life in US and UK adults. Int J Obes. 2015:39:1721-6.

23. Daly M, Robinson E, Sutin AR. Does knowing hurt? Perceiving oneself as overweight predicts future physical health and well-being. Psychol Sci. 2017; 28(7):872-81.

24. Robinson E, Sutin AR. Parental perception of weight status and weight gain across childhood. Pediatrics. 2016;137:e20153957.

25. Almond D, Lee A, Schwartz AE. Impacts of classifying new York City students as overweight. Proc Natl Acad Sci. 2016;113(13):3488-91.

26. Sutin AR, Stephan Y, Grzywacz JG, Robinson E, Daly M, Terracciano A. Perceived weight discrimination, changes in health, and daily stressors. Obesity. 2016;24(10):2202-9.

27. Nolan LJ, Eshleman A. Paved with good intentions: paradoxical eating responses to weight stigma. Appetite. 2016;102:15-24.

28. Calzo JP, Sonneville KR, Haines J, Blood EA, Field AE, Austin SB. The development of associations among body mass index, body dissatisfaction, and weight and shape concern in adolescent boys and girls. J Adolesc Health. 2012;51(5):517-23.

29. Tiggemann M. Body image across the adult life span: stability and change. Body Image. 2004; 1(1):29-41.

30. Loth KA, Watts AW, Van Den Berg P, Neumark-Sztainer D. Does body satisfaction help or harm overweight teens? A 10-year longitudinal study of the relationship between body satisfaction and body mass index. J Adolesc Health. 2015:57(5):559-61.

31. Neumark-Sztainer D, Paxton SJ, Hannan PJ, Haines J, Story M. Does body satisfaction matter? Five-year longitudinal associations between body satisfaction and health behaviors in adolescent females and males. Adolesc Health. 2006;39(2):244-51.

32. Sonneville KR, Calzo JP, Horton NJ, Haines J, Austin SB, Field AE. Body satisfaction, weight gain and binge eating among overweight adolescent girls. Int J Obes. 2012;36(7):944

33. Suelter CS, Schvey N, Kelly NR, Shanks M, Thompson KA, Mehari R, Brady S, Yanovski SZ, Melby CL, Tanofsky-Kraff M. Relationship of pressure to be thin with gains in body weight and fat mass in adolescents. Pediatr Obes. 2018; 13(1):14-22.

34. van den Berg P, Neumark-Sztainer D. Fat' $n$ happy 5 years later: is it bad for overweight girls to like their bodies? J Adolesc Health. 2007:41(4):415-7.

35. Fouts $\mathrm{G}$, Burggraf $\mathrm{K}$. Television situation comedies: female weight, male negative comments, and audience reactions. Sex Roles. 2000:42(9-10):925-32.

36. Lieberman DL, Tybur JM, Latner JD. Disgust sensitivity, obesity stigma, and gender: contamination psychology predicts weight bias for women, not men. Obesity. 2012;20(9):1803-14.

37. Robinson E. Overweight but unseen: a review of the underestimation of weight status and a visual normalization theory. Obes Rev. 2017;18:1200-9.

38. Ng M, Fleming T, Robinson M, Thomson B, Graetz N, Margono C, Mullany EC, Biryukov S, Abbafati C, Abera SF. Global, regional, and national prevalence of overweight and obesity in children and adults during 19802013: a systematic analysis for the global burden of disease study 2013. Lancet. 2014;384(9945):766-81.

39. Feng $X$, Wilson A. Neighborhood socioeconomic disadvantage modifies the relationship between weight status and weight-related satisfaction. Int $J$ Obes. 2016:40(12):1922-6.

40. Hochdorn A, Faleiros VP, Camargo BV, Bousfield AB, Wachelke JF, Quintão IP, Azzolina D, Gregori D. Obese children are thin in parents' eyes: a psychologically, socially, or culturally driven bias? J Health Psychol. 2018; 23(1):114-26.

41. Feng X, Astell-Burt T, Badland H, Mavoa S, Giles-Corti B. Modest ratios of fast food outlets to supermarkets and green grocers are associated with higher body mass index: longitudinal analysis of a sample of 15,229 Australians aged 45 years and older in the Australian National Liveability Study. Health Place. 2018:49:101-10.

42. Martin AA, Davidson TL. Human cognitive function and the obesogenic environment. Physiol Behav. 2014;136:185-93.

43. Watson $\mathrm{N}$, Wooden $\mathrm{M}$. The household, income and labour dynamics in Australia (HILDA) survey: wave 1 survey methodology', HILDA project technical paper series no. 1/02, May. Melbourne: Melbourne Institute of Applied Economic and Social Research, University of Melbourne; 2002.

44. Pink B. Socio-economic indexes for areas (SEIFA). Canberra: Australian Bureau of Statistics; 2011

45. Feng $X$, Wilson A. Do neighbourhood socioeconomic circumstances not matter for weight status among Australian men? Multilevel evidence from a household survey of 14691 adults. BMJ Open. 2015;5(9):e007052.

46. Feng $X$, Wilson A. Neighbourhood socioeconomic inequality and gender differences in body mass index: the role of unhealthy behaviours. Prev Med. 2017;101:171-7

47. Lovasi GS, Hutson MA, Guerra M, Neckerman KM. Built environments and obesity in disadvantaged populations. Epidemiol Rev. 2009;31(1):7-20.

48. Diez Roux AV, Mair C. Neighborhoods and health. Ann N Y Acad Sci. 2010; 1186(1):125-45

49. Kawachi I, Berkman LF. Neighborhoods and health. USA: Oxford University Press; 2003.

50. ARIA (Accessibility/Remoteness Index of Australia). [https://www. adelaide.edu.au/hugo-centre/services/aria]. Accessed 9 Aug 2012

51. Rasbash J, Browne W, Goldstein H, Yang M, Plewis I, Healy M, Woodhouse G, Draper D, Langford I, Lewis T. A user's guide to MLwiN; 2000.

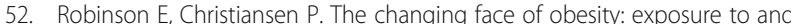
acceptance of obesity. Obesity. 2014;22(5):1380-6.

53. McLaren L, Gauvin L. Neighbourhood level versus individual level correlates of women's body dissatisfaction: toward a multilevel understanding of the role of affluence. J Epidemiol Community Health. 2002;56(3):193-9.

54. McLaren L, Gauvin L. Does the 'average size'of women in the neighbourhood influence a woman's likelihood of body dissatisfaction? Health Place. 2003;9(4):327-35. 
55. Ogden J, Mundray K. The effect of the media on body satisfaction: the role of gender and size. Eur Eat Disord Rev. 1996;4(3):171-82.

56. Benton C, Karazsia BT. The effect of thin and muscular images on women's body satisfaction. Body Image. 2015;13:22-7.

57. Krawczyk R, Thompson JK. The effects of advertisements that sexually objectify women on state body dissatisfaction and judgments of women: the moderating roles of gender and internalization. Body Image. 2015;15: 109-19.

58. Grabe S, Ward LM, Hyde JS. The role of the media in body image concerns among women: a meta-analysis of experimental and correlational studies. Psychol Bull. 2008;134(3):460.

59. Groesz LM, Levine MP, Murnen SK. The effect of experimental presentation of thin media images on body satisfaction: a meta-analytic review. Int J Eat Disord. 2002;31(1):1-16.

60. Swami V, Frederick DA, Aavik T, Alcalay L, Allik J, Anderson D, Andrianto $S$, Arora A, Brännström Å, Cunningham J. The attractive female body weight and female body dissatisfaction in 26 countries across 10 world regions: results of the international body project I. Personal Soc Psychol Bull. 2010; 36(3):309-25.

61. Barlow P, Reeves A, McKee M, Galea G, Stuckler D. Unhealthy diets, obesity and time discounting: a systematic literature review and network analysis. Obes Rev. 2016;17(9):810-9.

62. Zhang L, Rashad I. Obesity and time preference: the health consequences of discounting the future. J Biosoc Sci. 2008;40(1):97-113.

63. Wardle J, Griffith J. Socioeconomic status and weight control practices in British adults. J Epidemiol Community Health. 2001:55(3):185-90.

64. Dallman MF. Stress-induced obesity and the emotional nervous system. Trends Endocrinol Metab. 2010;21(3):159-65.

65. Dallman MF, Pecoraro NC, La Fleur SE, Warne JP, Ginsberg AB, Akana SF, Laugero KC, Houshyar H, Strack AM, Bhatnagar S. Glucocorticoids, chronic stress, and obesity. Prog Brain Res. 2006;153:75-105.

66. Marmot MG. Status syndrome. JAMA. 2006;295(11):1304-7.

67. Matud MP. Gender differences in stress and coping styles. Pers Individ Dif. 2004;37(7):1401-15.

68. Ptacek JT, Smith RE, Zanas J. Gender, appraisal, and coping: a longitudinal analysis. J Pers. 1992;60(4):747-70.

69. Tamres LK, Janicki D, Helgeson VS. Sex differences in coping behavior: a meta-analytic review and an examination of relative coping. Personal Soc Psychol Rev. 2002;6(1):2-30.

70. Donaghue N. The moderating effects of socioeconomic status on relationships between obesity framing and stigmatization of fat people. Fat Stud. 2014;3(1):6-16.

71. Fikkan JL, Rothblum ED. Is fat a feminist issue? Exploring the gendered nature of weight bias. Sex Roles. 2012;66(9-10):575-92.

72. Thomas SL, Hyde J, Karunaratne A, Herbert D, Komesaroff PA. Being 'fat'in today's world: a qualitative study of the lived experiences of people with obesity in Australia. Health Expect. 2008;11(4):321-30.

73. Puhl RM, Heuer CA. The stigma of obesity: a review and update. Obesity. 2009;17(5):941-64.

74. Brewis A, Trainer S, Han S, Wutich A. Publically misfitting: extreme weight and the everyday production and reinforcement of felt stigma. Med Anthropol Q. 2017;31(2):257-76.

75. Schuster RC, Han SY, Brewis AA, Wutich A. Increasing overweight and obesity erodes engagement in one's neighborhood by women, but not men. Prev Med Rep. 2018;10:144-9.

76. Levine MP. Loneliness and eating disorders. J Psychol. 2012;146(1-2):243-57.

77. Paeratakul S, White MA, Williamson DA, Ryan DH, Bray GA. Sex, race/ ethnicity, socioeconomic status, and BMI in relation to self-perception of overweight. Obes Res. 2002;10(5):345-50.

78. Dorsey RR, Eberhardt MS, Ogden CL. Racial/ethnic differences in weight perception. Obesity. 2009:17(4):790-5.

79. Mikolajczyk RT, lannotti RJ, Farhat T, Thomas V. Ethnic differences in perceptions of body satisfaction and body appearance among US schoolchildren: a cross-sectional study. BMC Public Health. 2012;12(1):425.

80. Wardle J, Haase AM, Steptoe A. Body image and weight control in young adults: international comparisons in university students from 22 countries. Int J Obes. 2006;30(4):644-51.

81. Rowland ML. Self-reported weight and height. Am J Clin Nutr. 1990;52(6): 1125-33. 